\title{
Tokyo Arts Festival, 2017, and International Shakespeare Productions
}

\author{
Tomoe KOMINE \\ Meiji University, Tokyo, Japan
}

\begin{abstract}
In 2017, the Tokyo Arts Festival invited theatre directors from three geographical locations to direct Shakespeare's plays: The British director John Caird directed Hamlet, the Romanian director Silviu Purcārete directed Richard III, and the Belgian director Ivo Van Hove directed a Dutch Othello. They approached Shakespeare's plays from unique perspectives, using their own native or Japanese language, working with Japanese and foreign actors and staff. They were performed in Tokyo and watched by various audiences. This paper examines the interactive effect of international theatre and the Tokyo Arts Festival and argues that Shakespeare, being a common currency in the world, functions as media for the Festival, and vice versa. While the Festival provides opportunities and support for foreign directors and companies, staging of international Shakespeare productions raises the profile of the Festival and promotes artistic and cultural programmes and exchange internationally. The audience also has much to gain: the Festival allows them to experience cultural differences and a reflection of themselves or of the world in works of art. The paper argues that the differences created in the international Shakespearean productions and realized and experienced by the audience are the essence of the theatre and meaning and value of the Festival.
\end{abstract}

Keywords: Tokyo Arts Festival, international theatre, Shakespeare, John Caird, Silviu Purcārete, Ivo Van Hove

\section{Literature Review}

Shakespeare is read and produced in many languages and countries. It has become a common currency in the world and an interest of many people to observe the transformation of Shakespearean text when interpreted by different readers, directors, actors, and staff of various backgrounds.

Patrice Pavis defines international festivals as those involved with the internationalization of exchange that made a "contribution to the accessibility of foreign works and established possibilities for intercultural penetration and exchange" (Pavis, 1996, p. 250). They allow people to meet, participate, see, and discuss, and respectful emulation raises standards. Nevertheless, Pavis has a rather negative attitude to the foreign productions involved in the festivals since they export a work "without any regard for the context in which it is presented" (p. 254). He fears that theatre work in a foreign country suffers from detachment from the original meaningful context.

While Pavis' concept of the "home" context would be British, it seems his concern especially involves issues of both "appropriation" and "adaptation." Choosing to quote the explanations that are fit for Shakespeare,

Tomoe KOMINE, Ph.D. (Literature), School of Agriculture, Meiji University, Tokyo, Japan. 
the $O E D$ explains adaptation as (2.a.) "[t]he process of modifying a thing so as to suit new conditions" and appropriation as (1) "[t]he making of a thing private property, whether another's or (as now commonly) one's own; taking as one's own or to one's own use." It has long inspired the theatre world with the question of whether we assimilate multiple readings without discrimination: what is a Shakespearean context that is acceptable for both home and external audiences? My answer to this question is that it can hardly be accepted by both sides, but this ambivalent tendency itself is the fundamental significance of the Arts Festivals.

Richard Schechner explains the movement of the world as shifting from a "nationalistic phase" to a "cultural phase" and tends to distinguish cultural areas, rather than national areas (Schechner, 1982, p. 3). In our globalized world, arts festivals transcend aesthetic and ideological boundaries in an attempt to create exchange between cultures by maintaining, not dissolving, cultural differences. Thus, art works have undergone vigorous changes, along with the recent rapid spread of culture. In the case of Shakespearean works, contrary to conservative people's wishes to protect the home context, they constantly undergo contextualization, appropriation, or adaption all over the world to suit each environment. In other words, what Pavis calls the "home" or "original" meaningful context of Shakespeare is bound to be altered as the textual context leaves its home context; it is exposed on a foreign ground, read, interpreted, translated, directed, acted, and observed by a multitude of people in various countries. Thus, a genuine Shakespeare adaptation is unlikely to be seen, and the home context of Shakespeare is not to be expected in international theatre. Rather, the audience is well aware of the change and perhaps expects to see a foreign context of Shakespeare in their own time and place, as Barbara Hodgdon claims, "We are never 'in' Shakespeare's world but in our own, collaborating with him over time and from a distance" (Hodgdon, 2005, p. 159). Thus, the natural alteration of the context is welcome at the Arts Festivals; in fact, the various differences add fun and value to the Festivals. Since Shakespeare can provoke and inspire the artists and audience, it must work to connect art forms, people and ideas.

Shakespeare is globally staged in different cultures and with different interpretations. This importation and trading of Shakespeare may lead to its transformation. The staging of Shakespeare as a common currency in the festivals and views of different contexts should be the real purpose of the Arts Festivals. In other words, the realization and acceptance of differences represents the actual achievement of the Arts Festivals.

\section{Tokyo Arts Festival}

The Tokyo Arts Festival lasted 74 days, from 22 September to 4 December, 2017. According to the Festival organization homepage, the Festival has three main purposes:

(1) to link the metropolis to the world through the rich arts and culture of Tokyo;

(2) to showcase the appeal of Tokyo's arts and culture;

(3) to enhance Tokyo's own artistic creativity.

In the long run, it also aims to develop human resources and resolve social issues in a globalized society.

The sites used for various artistic activities include the Tokyo Metropolitan Theatre, Owlspot Theatre, Minami Ikebukuro Park, and other public places and parks situated in the Ikebukuro area of the Toshima Ward. Ikebukuro is a large city, where there are many business enterprises, shopping malls, and schools, and it has recently become an international city where many foreign people reside and study.

The four projects play key roles in supporting the Tokyo Arts Festival: Festival/Tokyo 2017, Tokyo 
Metropolitan Theatre Autumn Selection, TOSHIMA International City of Arts \& Culture Program, Asian Performing Arts Forum (APAF), all working for the common purpose of promoting the appreciation and appeal of the performing arts in Tokyo. The Festival organizer is the Tokyo Metropolitan Festival Executive Committee, which consists of the Arts Council Tokyo, Tokyo Metropolitan Theatre (Tokyo Metropolitan Foundation for History and Culture), Toshima City, Toshima Mirai Cultural Foundation, Festival/Tokyo Executive Committee, and Asian Performing Arts Festival Executive Committee.

One of the committee members, the Arts Council of Tokyo, plays an especially significant role in Tokyo's cultural policies and conducts projects that serve as the driving force of cultural programmes. One of the purposes of their activities is to develop "a variety of programs to encourage the creation and dissemination of arts and culture and to promote Tokyo as an international city of artistic and cultural attractions." They also promote projects for the run-up to the 2020 Tokyo Olympic and Paralympic Games and provide financial support to organizations to represent art and culture in Tokyo nationally and internationally. The types of grant funding include the Arts Council Tokyo Grant Program, Regional Grant Program, Social Grant Program, and Tokyo Tokyo Festival Grant Program, the last of which especially targets international activities and cultural exchange that enable many people to participate and raise the profile of Tokyo as an international metropolis. For the above purposes, the Arts Council of Tokyo cooperates with artistic and cultural organizations, non-profit organizations, and private-sector businesses and promotes artistic and cultural activities in Tokyo.

\section{The Three Shakespeares of the Tokyo Arts Festival}

The three foreign Shakespearean productions at the Tokyo Arts Festival, 2017, were all different in their approaches and provided us with an opportunity to reconsider the significance of further development of intercultural theatre in our globalized world. Below, I shall provide an outline of how each production was staged and review how they interacted with the Japanese actors or stage and appealed to the audience.

John Caird, a well-known British director, directed Hamlet (2017) at the Tokyo Metropolitan Theatre. It was staged 19 times in Tokyo between 9-28 April, 2017, before touring around Japan the following month. While his Twelfth Night, produced in 2015, was a westernized production, Hamlet was performed in the Noh-style, with Japanese actors (many of them popular TV actors) speaking the lines translated into Japanese by Kazuko Matsuoka, though many lines were cut and the translation was altered to suit Caird's needs. It was set on a Japanese Noh theatre-like stage, with the actors sitting on the right side of the stage watching the other actors play their parts on the platform in the middle, while the audience sat on the left side of the stage, watching the actors acting their parts and being watched by the other audience in the auditorium. The music was rendered through the Japanese instrument Shakuhachi by Fujiwara Dosan, and the actors wore a mixture of Asian and European costumes. Caird's British reading of Hamlet was framed within the Japanese Noh stage and setting, delivered by Japanese actors, and watched by a mixed audience.

The biggest selling point of this production was the style by which the actors played double roles. In fact, double-casting through the quick change technique is common in kabuki; in 2007, Ninagawa had already applied it to Shakespeare's Twelfth Night, in which Kikunosuke Onoe, a kabuki actor, played both Viola and Sebastian, using a quick change technique. However, Caird's metatheatrical production seemed to be more complex in its application of multiple layers of readings. For example, Jun Kunimura, the actor who played Claudius, was also 
cast as the ghost (Hamlet's father), playing both a man suffering from guilt and a man with grudges against his mortal enemy. In the Hamlet/Fortinbras double-casting, as soon as Hamlet (played by Seiyo Uchino) dies, he gets up and starts speaking the lines of Fortinbras, thus, indicating the continuation of rule over Denmark.

In the production interview, Caird states that his intention was to show that the play was about acting; that is to say, by setting the play in a metatheatrical setting and allowing the actors to play double roles, Caird intended to delve deep into the characters' psyche. For example, by double-casting the actors, Seiyo Uchino's representation of the mind of Hamlet can be studied against his Fortinbras', or vice versa, and Jun Kunimura's Claudius can be counter-examined with the ghost. The visibility of the characters on stage is not the whole; the invisible superego is also noticed in Caird's production.

Moreover, several layers of casting are observed in Polonius and Ophelia: Polonius becomes the grave-digger who digs his (Polonius') own daughter's grave; Ophelia, whose ghost has been walking around the platform after her death, suddenly becomes Osric, who serves Laertes to put poison on the sword that kills Hamlet. In other words, while the psyche of the father and the daughter can be observed, their superegos can also be examined. The double-casting production has Polonius reborn in the form of a grave-digger to take care of his daughter until she is properly buried; Ophelia lives on in the figure of Osric to help her brother kill Hamlet. Whether the production indicates Ophelia's wish to revenge Hamlet for her family or her hasty desire to invite her beloved to join her in the next world, the destiny seems set for the characters, and Ophelia is reborn as a ghost, then as Osric, not to change Hamlet's destined route but to hasten it. The complex world is represented by the actors who act and keep a very close watch on their destined route off-stage. The production shows that the characters may be reborn in different forms, but they are merely part of the predetermined course of events.

Horatio is the only character who is not double-cast, thus, bearing the responsibility to pass the story down to the next generation and to guard the destined route of the characters. Noh stages the spiritual world of both the living and the dead: if Horatio's part functions as "Utai" in Noh, who sings to proceed the Noh storyline, then the other invisible characters who are off-stage function as "Jiutai" to sing out, from the third person's point of view, the inner thoughts of those who are off-stage.

Caird's direction seems to indicate the idea of a dying person leaving behind a tenacious mind for an unfulfilled mind. In Buddhist terms, he/she has not entered Nirvana, and the soul does not rest in peace. It indicates the Japanese idea of lives being in flux through the endless circle of birth, death, and rebirth, and the stage shows us that the characters drag their thoughts into the next world. The Noh stage assimilates Shakespeare's Hamlet and harmonizes with Caird's direction.

After Caird, the Tokyo Metropolitan Theatre Autumn Selection organized four programmes, two of which were foreign Shakespearean plays, with an aim to open a path to new expression. The Romanian director, Silviu Purcarěte, directed Richard III. The production consisted of 15 Japanese actors who played both male and female characters, and one actress dressed like the Bard, carrying a book and a quill, appeared between the scenes and commented on the play.

The bare stage was surrounded by high concrete walls, creating a cold unfriendly air on stage. As the curtain was drawn, we witnessed Purcarĕte's excellent handling of the masses. The play began with a noisy party of drunken men, singing, dancing, stamping their feet, and frantically shouting and screaming out their lines. The mass of people speaks their Shakespearean lines deliriously, yet their rhyming couplet sounds like they are 
playing music together. The musicality of Shakespearean words, even in Japanese translation, is brought out by Purcarěte's direction.

The dramatic characters in relation to the principles of Yin Yan were portrayed psychoanalytically. Kuranosuke Sasaki's Richard of Gloucester is among the crowd of frantic men, but as he suddenly stops his movement, all the noise, music, and dancing stop. Then, Sasaki picks up a walking stick, bends forward to become a hunchback, and starts to speak his first line. Sasaki exaggerated Richard's falseness and socio-pathetic personality: in his Richard, the physical deformity and emotional instability are fake. For example, he woos Anne in a business-like manner and almost as if he despises her, and in his wooing, he changes his standing posture from the deformed Richard to a tyrannical male. Moreover, in the scene in which Richard campaigns to the Mayor of London and civilians over his right to the throne, the stage shows us the inside of the building, where we witness Richard's reactions and movements, while we hear only the voice of the Mayor from the back of the stage. Richard looks slovenly with his naked upper body, heavily drinking bottles of wine and devouring food from a bucket, indicating his suffering from hyperphagia. When the time comes for him to speak, he sticks his head out of the door and speaks solemnly to the Mayor of London, while his hands, visible from the audience, grab bottles and a spoon restlessly.

This contrast between Richard's unstable and lonely private life and dictatorial public figure is further represented by Sasaki's contrasting movements: when he is alone on stage, he cuddles into the vinyl sheets and sleeps like an embryo in his mother's womb, but he rips the sheets open and uses them to suffocate other characters, including the princes (Edward IV's sons). Thus, the actors' movements, gestures, and means of delivering speech all collaborate to support the following dialogue between Richard and Buckingham:

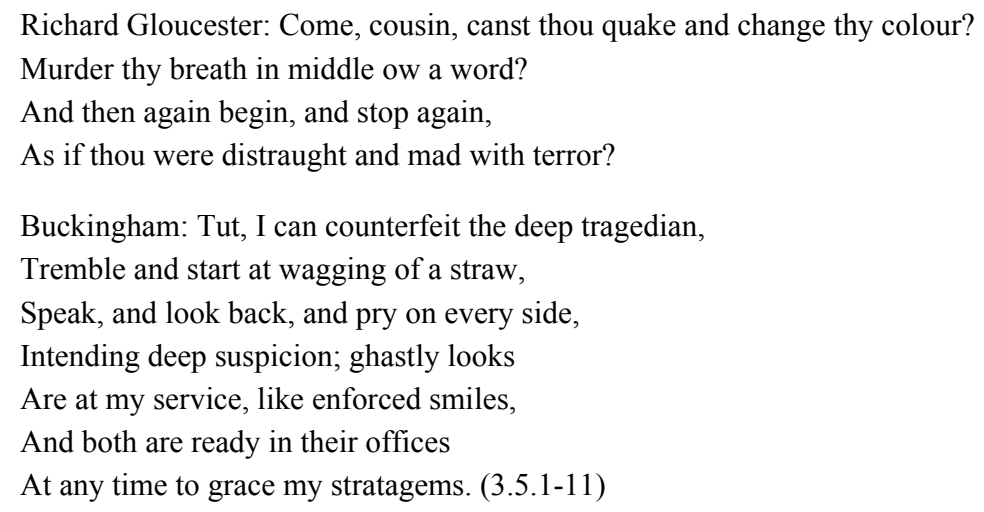

Both Sasaki (playing Richard) and Takashi Yamanaka (playing Buckingham) act their roles as if they are having fun playing a game of pretence: they do not show any guilt at reducing people to despair and manage to commit crimes with ease.

On the other hand, Richard's dichotomic nature appears to be due to his fear of the power of the crowd, which was one of the emphasized features of this production. The crowd in Purcarěte's production functions like the chorus in Greek plays and has power over Richard and the plot, overwhelming and controlling them. Sasaki's restless Richard is not afraid of tricking people but appears to be conscious of the reaction of the crowd.

At the same time, the falseness of the female characters' gender is clearly manifested. Toru Tezuka plays Anne and limps uncomfortably in a bright red dress and very high heels, while his female lines are delivered in 
the high false tone of a male voice. Lady Elizabeth Grey, Edward IV's widow, played by Jun Uemoto, first appears gracefully covered in a long black veil and dress, but once he takes off his veil, his bald head and well-built body are revealed. With such an appearance, his mismatching white make-up stands out to make him seem grotesquely comical. Margaret is played by Tomohiko Imai, whose face is painted like a skull, and like Anne, limps in high heels and later wanders around the stage as an ill-fated ghostly figure. This group of women with their unnatural make-up, false voices, and behaviour, emphasizes their monstrosity when they deliver their lines in chorus. Their falseness makes the whole production seem like an absurd game they are playing, and their chorus power veils the stage with an unearthly air.

Nevertheless, when they confront Richard individually rather than as a group, they are reduced to lonely feeble figures. The chorus loses power before Richard, who knows how to control the crowd with a dichotomic nature: when Anne is wooed by Richard or pretends to be wooed, she appears well aware of Richard's falseness but submits to her fate. The anger that Lady Elizabeth Grey expresses is repelled, and Margaret's malice is sneered at. The audience is betrayed when we find out that the chorus of women is not as powerful as it first seemed, after all.

Emphasis on the trust or doubt of the crowd and individuals makes us wonder if the director's Romanian background, having experienced the period of Romanian revolution, has anything to do with the representation of the power of the crowd against a dictator. Although he does not speak much about his directorial intentions, the issue of the masses and individuals is a distinguishing feature of Purcarĕte's other theatrical and operatic productions, including Faust (2014) and Phèdre (2014), which are remembered as being original and free. Purcarěte represented the crowd of people like the Greek chorus. By blurring the border between the people and the gods, Purcarěte made the power relationship among the individuals, crowd, and gods obscure yet interactive.

As for Purcarĕte's intentions for his Richard III play, he commented in the production interview that there is no point in directing a Shakespearean play exactly like British directors. Indeed, it was a production to illustrate international involvement: a Shakespearean text was read and interpreted by a Romanian director, directed from his perspective, acted by Japanese actors, and watched by multiple audiences. This means that, already at this stage, it is a diversified Shakespeare that the audience is being offered. Moreover, by showing the binary aspects of real/fake characters, true/false situations, real/unreal worlds, Yin and Yan aspects of the production are manifested and the audience is provided with various perspectives from which to observe the production, with unlimited interpretations.

Finally, another production, Othello, was directed by Belgian director Ivo van Hove, who works for the Dutch Toneelgroep Amsterdam theatre group. Unlike the other two productions previously mentioned, all actors in this production were Dutch and spoke Dutch with Japanese subtitles at the side of the stage.

The director, Van Hove, was especially concerned with the issue of otherness in Othello, which he considers to be the core of the play. He entrusted the translation to a Moroccan Dutch, Hafid Buazza, who translated the text into Dutch, since Van Hove believed only Buazza could translate the text while maintaining the emphatic idea of difference in the play, thus ensuring that the idea of discrimination in Othello was included.

The production focused on the Arab qualities of Othello, and there were frequent references to Arab culture. For example, an Arab poem is sung by Ophelia, and Arab symbols such as the moon (which symbolizes a beautiful lady, thus, Desdemona) and a handkerchief (which symbolizes honour) are referred to. By emphasizing 
Othello's Arab roots, a foreigner in Venice, the production shows the irony that while Othello's skills in war are praised, his foreign racial roots are disregarded in the two-faced world of Venice. On the other hand, the actors playing such characters are standardized; they are all white men dressed in army uniforms speaking Dutch, and hardly any external differences are seen, in comparison to the emphatic Arab nature of Othello.

This modernized production gives us various audio-visual hints to the director's intentions when contextualizing the play. The scene in which Othello suspects and denounces Desdemona's faithlessness takes place in a small glass-walled container. It represents their bedroom and is sound proof; their arguments, including Othello's shouting and Desdemona's screaming before and during the strangulation are all heard indirectly through a microphone. The audience's view of the scenes is sometimes restricted by the actor playing Othello, who draws the curtain now and then. At the same time, a fight between Iago and Cassio takes place behind the container at the back of the stage, but we cannot hear them speak; we only see Cassio being thrown against a wall and bleeding to death. In both the play's political and domestic worlds, the violence is almost always visible, but the words are unheard.

This production emphasizes the visibility of the plot and actions, but this may not be all there is. Visible differences are not the only reasons for discrimination; invisible differences or unheard comments may be hidden behind the visibility. The production reflects the political and social changes in our modern world and allows us to feel the times. Thus, discrimination can occur anywhere on stage (as in our world), and the audience can find the clues if they look for and feel them.

As is suggested by the production, the audience may realize that we all live in the world of difference and discriminations with which our world of political and environmental turmoil is filled. In such a complex world, where differences are rejected and eliminated, harmonization seems impossible to achieve, resulting in the tragedy of Ophelia and Othello.

To sum up the three productions, Caird's double-casting in Hamlet represents the visible and invisible worlds, indicating the world of the dead and that of the living, while staging it on the Noh stage means that the ideology behind Caird's direction is in tune with the Japanese Noh stage. Purcarěte's Richard III emphasizes the antipathy of the masses and the individual, and while it seems that Richard's individuality conquers the crowd of people, it is in fact the individuals who are embroiled in the power of the masses. Van Hove's Othello production shows the literally visible world against the supposedly invisible world, or spoken words against unheard words inside and outside the box, on and off stage, in and out of the theatre or even the world, indicating what we believe we see or hear may not be so; we may be aware of superficial aspects but do not really see/hear the quintessence.

\section{Conclusion}

Caird's Hamlet, Van Hove's Othello, and Purcarĕte's Richard III, all played at Tokyo Arts Theatre for the Arts Festival, 2017, approach Shakespearean plays from different perspectives. The English language was not used, and English actors were not involved, but foreign and Japanese directors, actors, and languages collaborated to produce multinational productions in Tokyo. While they all have different cultural backgrounds and reasons or means of contextualization, a common issue was raised and noticed: characters' worlds may be visible or invisible, and their words may be heard or unheard, real or artificial. The message received depends on the audience attempting to hear and see them. The audience may realize the significance of reflecting the world or 
themselves in art and culture, or vice versa.

As Peter Brook claims that it is the "Shakespearean ambition" that is significant for us, the "quintessence" of human existence (Brook, 1987, p. 55), we may learn through Shakespeare's prominent stance and gaze. This takes us back to the thesis statement of this paper that it is indeed the cultivation of observation of various views and the realization of differences that are necessary to learn from both Shakespearean theatre and Arts Festivals.

Shakespearean theatre is a medium through which different cultures meet and interact. The Tokyo Arts Festival enables the involvement of different people and cultures in the collaboration and works towards internationalization of the metropolis, acceptance of different values, and provision of opportunities for people to see and experience new things and to journey into and challenge the unknown. From such perspectives, one might say that the Tokyo Arts Festival 2017 was an experimentally challenging festival to stage different productions branching out from Shakespeare, an artistic culture that is familiar to many people. The highest attainment of the internationalization of theatre at the Tokyo Arts Festival may be the elimination of any unnecessary borders for artistic creation and cultural exchange, thus, preparing to build momentum for the 2020 Olympic and Paralympic Games and beyond.

\section{References}

Arts Council Tokyo. Retrieved from https://www.artscouncil-tokyo.jp/ja Brook, P. (1987). The shifting point 1946-1987. London: Harper \& Row.

Hodgdon, B. (2005). Afterword. In S. Massai (Ed.), World-wide Shakespeares-local appropriations in film and performance (pp. 157-160). London: Routledge.

Pavis, P. (1996). Introduction. In P. Pavis (Ed.), The intercultural performance reader (pp. 1-21). London and New York: Routledge.

Schechner, R. (1982). Intercultural performance. The Drama Review, 26(2), T94.

Tokyo Festival. 2017. Retrieved from http://tokyo-festival.jp/2017/program

Tokyo Festival. 2018. Retrieved from http://tokyo-festival.jp/2018 